\title{
Intellectual Capital's Leverage on Shareholder Value Growth: A Lesson for Developing Economies
}

\author{
Bongani Ngwenya* \\ Solusi University, Zimbabwe \\ *Corresponding author: ngwenyab@solusi.ac.zw \\ Received January 07, 20113; Revised May 23, 2013; Accepted May 24, 2013
}

\begin{abstract}
The purpose of this study is to evaluate whether there is a correlation between the intellectual capital of employees, i.e. top managers (the agent) and the shareholder (the principal) value growth among Zimbabwean companies, listed on the Zimbabwe Stock Exchange. By using these results the aim is to further examine a possible indicator for leveraging the efficiency of intellectual capital in a developing economy as a lesson. In order to perform this investigation, intellectual capital and shareholder value are quantified with, respectively, value added per employee and share price value per employee. These measurements are gathered from 17 Zimbabwean listed companies, divided into five industry sectors, that is, services, manufacturing, agriculture, mining and information technology, and tested statistically in order to find a relationship. This means, according to the researcher`s propositions on the return on intellectual capital, that there also is a correlation between intellectual capital and shareholder value growth. In order to provide an indicator for improving companies' intellectual capital, a statistical examination concerning the relationship between the Intellectual Capital Multiplier (IC Multiplier) and value added is also performed. This examination shows that there is a strong correlation between the IC Multiplier and value added, value added can to a degree of 84 percent be predicted by the IC Multiplier, and that working with the ratio between structural and human capital is an excellent method for companies in developing economies to increase their intellectual capital. In conclusion it can be said that most companies in this investigation show moderately low values regarding the IC Multiplier, leading to an erosion of the companies' human capital. In order to become more stable and lower the degree of risk, these companies must improve their IC Multiplier. What this study demonstrates is that an improvement of the IC Multiplier also will have an extensive effect on the company's shareholder value growth.
\end{abstract}

Keywords: intellectual capital, value added per employee, structural capital, human capital, IC multiplier, shareholder value growth

\section{Introduction}

The economies and individual companies have slowly transformed during the last few years, such that many companies of today have realized that their prime assets no longer consist of real estate and machine parks [1]. The author further asserts that innovation and above all, knowledge of the workforce has hence evolved into one of the economy's prime resource, more important than raw material and sometimes more important than money itself. Empirical evidence reveals that knowledge, like other physical and financial corporate assets that are firm specific, creates shareholder value and is generally expected to generate above-normal benefits [2]. Information age companies or knowledge companies do not hire people for their physical abilities but for the ability to exploit their knowledge that is, intellectual capital.

Literature is very clear with evidence that many practitioners and scholars agree that Intellectual Capital is of major importance, however a few are able to define and quantify it [3]. Some literature argues to the effect that, "One searches for measures of intangibles value in order to provide new information to managers and investors.
What is the use of a measure that is derived from what investors already know? Estimating the value of intangible assets, through a different approach, is naturally something that seems of great importance". Furthermore, the lack of means concerning the ability to make the Intellectual Capital visible leads to an inefficient basis for decisions for investors [4].

The researcher believes that the importance of Intellectual Capital and its measurement will grow substantially in the future and that this issue demands further enlightening through further future research.

From here the researcher proceeds by way of discussing briefly the problem, highlights the research questions and suggested propositions or hypotheses, and reviews literature that informs the theoretical frame work of the study. After literature review the researcher discusses the research methodology employed in the study, data analysis and then finally highlights conclusions drawn from the study and recommendations thereto.

\section{Problem Discussion}

Gone are the times when physical or tangible assets were the prime resources to steer desired performance of firms. In the knowledge economy that has risen, most 
companies now base their business on knowledge, compared to formerly, in which physical assets were regarded as only the prime resources. Some scholars in fact, suggest that in today's economy, all firms are knowledge companies [5]. The knowledge is possessed by the employees who convert it into value depending on their capabilities and the right support offered by the company. Several researchers reiterate that focus should now shift from cost control efforts to value addition strategy. In other words in order to manage and understand value creation within companies more modern management methods and new measuring tools are needed [6].

To conduct this study the researcher is making important assumption regarding the measurement of intellectual capital. The researcher uses Value added per employee as an approximation of the return of intellectual capital. The main question is how do companies manage to do this equally well and do the financial markets acknowledge this effort?

However in today's economy where the majority of the companies' value laid in their Intellectual Capital the main research question can be further divided into subquestions formulated as follows?

1. Is there a relationship between the value of companies`Intellectual Capital and their market value?

2. Is there a relationship between Intellectual Capital and market value of the company easier to determine when companies within the same industry sector are compared?

3. Is the relationship between Intellectual Capital and market value of the company affected by the size of the company?

4. Does company age has any effect on the relationship between Intellectual Capital and market value of the company?

5. Is there any relationship between the companies` IC Multiplier and the companies` market value?

From the questions above the researcher has attempted to define the following proposition:

Proposition 1: There is a significant relationship between companies' value added per employee and their share price value per employee when comparing all the selected companies.

Proposition 2: There is a significant relationship between companies' value added per employee and their share price value per employee when comparing companies by industry sector.

Proposition 3: There is a significant relationship between companies' value added per employee and their share price value per employee when comparing companies divided by company size.

Proposition 4: There is a significant relationship between companies' value added per employee and their share price value per employee when comparing companies divided by company age.

Proposition 5: There is a significant relationship between companies' IC Multiplier and their value added per employee.

\section{Literature Review and Theoretical Framework}

\subsection{The Intellectual Capital Perspective}

The Intellectual Capital perspective has its origins grounded firmly within the practitioner and have evolved through practice. The two authors suggest that Intellectual Capital was pioneered in the early 1990s by a group of companies around the world. These were led by Skandia, a Swedish Financial Services firm [7]. Intellectual Capital perspective emerged as a result or response to the frustrations caused by traditional management tools and their ability to leveraging intangible [7]. The concern of these companies had been of a new language and framework that would allow them to address the issues surrounding the true drivers of value creation in knowledge intensive firms. The main argument during this time was that the dominating financial view of the firm, which was the fundamental base of the management theories and tools by then, was not able to provide these companies with a comprehensive perspective of their process for creating value. The accounting framework therefore provides little guidance in understanding and managing the firm`s intellectual resources and their effect on value creation [7].

Several academics have adopted the Intellectual Capital perspective as a useful framework for describing all of the resources a firm has at its disposal to create value[8-14]. It is suggested that some theoretical underpinnings of the Intellectual Capital literature draw on aspects of resources-based theory from the strategic management literature $[7,15]$. Thus, the Intellectual Capital perspective offers a bridge between the conceptual thinking of the resources-based theory and a practical approach necessary for the adoption of the framework by managers.

\subsection{Intellectual Capital}

In the section above the researcher attempted to describe the perspective of Intellectual Capital. However in this section the researcher seeks to define Intellectual Capital. The definition of Intellectual Capital is far from obvious, because the opinions regarding which components to be included differ to a large extent depending on the researcher [1]. The most common and straightforward definition of Intellectual Capital may well be, as stated earlier, the gap between market value and book value. There have been attempts to estimate the value of intangible assets by using the difference between the market value and the book value of companies [3]. This has, however proven to be inadequate since this approach is based on two incorrect assumptions. The first assumption is that the financial markets are efficient (the efficient market hypothesis), i.e. there exist no mispricing of shares, for example. The second incorrect assumption is that the assets on the balance sheet reflect their current values [3].

In some literature [4] Intellectual Capital has been defined as "a combination of human capital - the brains, skills, insights and potential of those in an organization and structural capital - things like the capital wrapped up in customers, processes, databases, brands and IT systems. It is the ability to transform knowledge and intangible assets into wealth creating resources, by multiplying human capital with structural capital”. Skandia was a pioneer in the area of defining, measuring and working with Intellectual Capital. They provided one of the initial classification schemes and their definition of Intellectual 
Capital was "the possession of knowledge, applied experience, organizational technology, customer relationships and professional skills" which later on has been simplified to human capital plus structural capital equals intellectual capital [4].

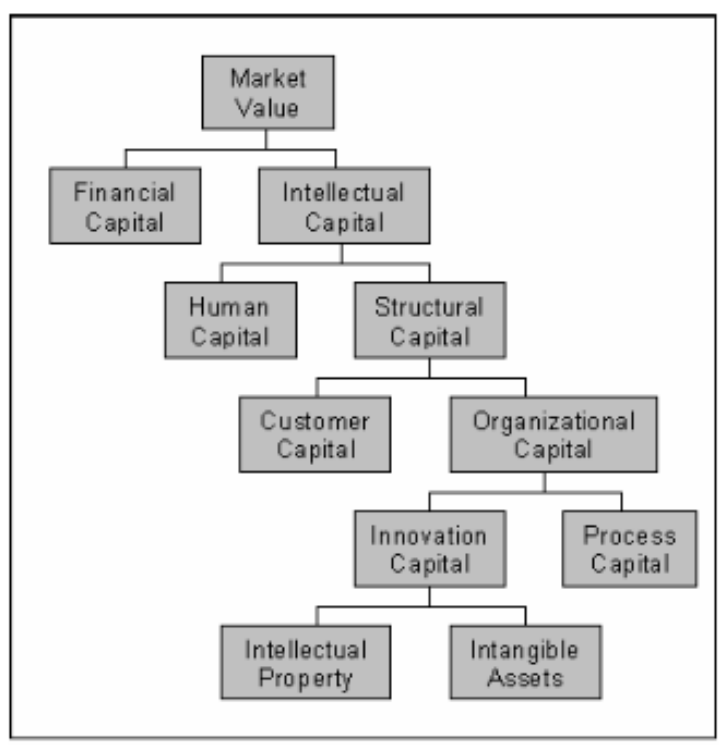

Figure 1. The Skandia Market Value Scheme

Source: Johnson (2002)

Human Capital + Structural Capital $=$ Intellectual Capital

Literature depicts this definition of Intellectual Capital as one of the most widespread and very practical. Intellectual Capital is the economic value of two categories of intangible assets of a company, i.e. organizational (structural) capital and human capital [16]. This definition has since its creation, been further developed [1]. The following authors have [15] developed one model regarding Intellectual Capital management. Their model or "Value Platform" as it is also called, can best be described as a development of the model used by Skandia, but distinguishes Customer Capital from the previous two components [18]. They further suggest that it is not enough to merely include the three components individually. Instead they have to be grouped so that they enhance each other. In other words the value does not arise from the separate components of Intellectual Capital, it takes place in the interplay or interaction between them and they are all equally important for this value creation [4]. The Skandia Market Value Scheme also comprehensibly illustrates the structure of the components of Intellectual Capital, as shown in Figure 1 below. That is, Intellectual Capital is divided into Human Capital and Structural Capital. Structural capital is further divided into Customer Capital and Organizational Capital and Organizational Capital in turn, is divided into Innovation Capital and Process Capital, etc.

\section{Research Methodology}

Following quantitative research method, the sampling plan was purposeful $[16,17]$. Seventeen Companies listed in the Zimbabwe Stock Exchange were selected from the services, manufacturing, agriculture, and mining and information technology sectors of the economy. The research sampling selection began with the group of firms in the manufacturing sector because they consist of the largest number of listed companies, followed by agriculture, mining and then information technology. Of the 12 manufacturing firms that met the purposeful criterion, 7 were selected for the purposes of this study. All the 5 agric-based firms were selected, 3 from the mining sector and 2 from the information technology sector. A total of 53 top managers comprising Chief Executive Officers or Managing Directors, Chief Financial Officers, Chief Operations Officers and Human Resources Officers participated in this study as employees. The study sought to investigate if there is a relationship between the value of intellectual capital and market value of the firm, and also between the Intellectual Capital Multiplier (IC Multiplier) and the value of intellectual capital. To achieve these measurements the researcher applied the Value Added Approach over a period of five years. That is, Value added per employee as a measure of the return of intellectual capital and the stock exchange value (share price) as a measure of company`s market value and hence shareholder value.

\section{Analysis of Data}

The researcher used the spreadsheet program MS Excel to calculate the figures into statistical observations. In order to find relationship between value added per employee (intellectual capital measure) and stock exchange value (Share price/shareholder value) regression analysis was performed as the main statistical method for presenting and analyzing the figures. All regressions were analyzed to see whether there was any statistical significance. In order to test the propositions the researcher`s first step was to find adequate measurements for quantifying company's Intellectual Capital and market value. The researcher chose Value added and Stock exchange value, both divided by the number of employees to be able to compare companies of different sizes. Share price or Stock exchange value per employee (SEV/e) is rather self-explanatory for measuring market value of a company. However Value added per employee (VA/e), as an approximate measurement of a company's return of intellectual capital, might nevertheless need some additional explaining. Value added is the additional value, which is created within the company by using value added per employee; one can get an impression of how many individual employees contribute to this value [17]. For the purposes of this study the researcher used the most established definition, which is operating profit before depreciation and personnel costs divided by number of employees [18].

Table 1 below presents some statistical descriptions for the entire observed secondary information, i.e. all selected companies and years. The mean value for the Intellectual Capital measure (VA/e) is 1371 while the Stock exchange value per employee (SEV/e) is more than four times higher at 5 282. The median suggests the following observations that can be made regarding the difference between VA/e and SEV/e. The difference is less than three times greater for SEV/e. Notable is further that the difference between the mean and median value has been halved when observing VA/e. This indicates that the Mean 
value could be somewhat misleading, at least regarding VA/e.

Table1. Statistical Descriptions for the Entire Observed Data

\begin{tabular}{|c|c|c|}
\hline & VA/e & SEV/e \\
\hline Mean & 1371 & 5282 \\
\hline Median & 719 & 1936 \\
\hline Standard deviation & 1836 & 8209 \\
\hline Largest & 8567 & 60743 \\
\hline Smallest & -449 & 236 \\
\hline
\end{tabular}

The standard deviation indicates that the spread around the mean of SEV/e is greater than that of VA/e, i.e. 8209 and 1836 respectively. It is clear indication that the stock exchange value is more volatile than the value added, which may not be a surprise to most people. This volatility is also clearly seen when observing the largest and smallest observation for VA/e and SEV/e. The largest value of VA/e is 8 567, while that of SEV/e is as high as 60 643, a difference of more than seven times, however in contrast to the smallest values of VA/e and SEV/e which are, -449 and 236 respectively.
The following statistics summarizes the regression analysis and indicates that there is a correlation between VA/e and SEV/e on the entire observed data; on decision scope (Summary Model);
a). Predictors: (Constant), data collection
b). p-value=3.73E-39
c). Significant level= 95\%
d). Beta Value of 0.79 (Coefficients)
e). Adjusted R, squared $=0.62$

\subsection{Industry Sectors}

The researcher sought to illustrate in more detail the observations discussed above by dividing the data into separate industry sectors. From Table 2, below the sector with the highest values in mean is Agriculture with regard to both VA/e and SEV/e, at 3129 and 11 508. In contrast the sector with the lowest mean values is Information Communication and Technology, with VA/e at 526 and SEV/e at 1315 respectively. These trends also include the median values, for each measure.

Table 2. Statistical Description, by Industry Sector

\begin{tabular}{|c|c|c|c|c|c|c|c|c|c|c|}
\hline & \multicolumn{2}{|c|}{ Services } & \multicolumn{2}{|c|}{ Manufacturing } & \multicolumn{2}{c|}{ Agriculture } & \multicolumn{2}{c|}{ Mining } & \multicolumn{2}{c|}{ I Technology } \\
\hline & VA/e & SEV/e & VA/e & SEV/e & VA/e & SEV/e & VA/e & SEV/e & VA/e & SEV/e \\
\hline Mean & 625 & 1414 & 806 & 4360 & 3129 & 11508 & 711 & 3298 & 526 & 1315 \\
\hline Median & 615 & 1401 & 756 & 2074 & 2579 & 10684 & 719 & 2310 & 515 & 1301 \\
\hline Standard deviation & 247 & 831 & 365 & 6103 & 2691 & 12299 & 303 & 2993 & 147 & 731 \\
\hline Largest & 1189 & 3942 & 1427 & 29775 & 8567 & 60743 & 1010 & 17084 & 1089 & 3842 \\
\hline Smallest & 332 & 337 & 356 & 433 & 458 & 236 & -449 & 964 & 232 & 237 \\
\hline
\end{tabular}

The Standard deviation for SEV/e, as observed in the table above is highest for the Agricultural, more than double compared to the next sector in line; Manufacturing. The IC Technology sector demonstrates the smallest standard deviation. Regarding the standard deviation of VA/e, the three sectors Services, Manufacturing and Mining are all approximately centered on 300. However, Agriculture once again shows indicators of diversification compared with the other sectors since its standard deviation prove to be 2 691. The researcher believes the main reason for this large standard deviation concerning VA/e is caused by the sector being the main back bone of the Zimbabwean economy. Agriculture on the one hand, contains companies characterized of few top managers and large amounts of financial capital. These factors naturally influence, to a large extent, the values of VA/e and SEV/e since they are calculated per employee. An interesting observation, concerning the smallest values observed, is that the Mining sector holds the smallest lowest VA/e of the four sectors, at -449 . In contrast, this sector also holds the highest SEV/e at 964, in the smallest category.

The same discussion above, concerning VA/e and the average amount of total salary per employee (salary/e) could be applied here as well. The average salary cost per employee compared to VA/e can be seen in Table 3 below. As can be seen in the table, the Agricultural sector demonstrate the largest difference of 2626.

The following statistics summarizes the regression analysis and indicates that there is a medium strong correlation between VA/e and SEV/e on an industry sector basis; on decision scope (Summary Model);

a). Predictors: (Constant), data collection

b). $\mathrm{p}$-value $=0.083$

c). Significant level=95\%

d). Beta Value of 0.25 (Coefficients) e). Adjusted R, squared $=0.06$

Table 3. The Salary per employee share out of Value Added per employee

\begin{tabular}{|c|c|c|c|c|c|}
\hline & Services & $\begin{array}{c}\text { Manufact } \\
\text { uring }\end{array}$ & $\begin{array}{c}\text { Agricult } \\
\text { ure }\end{array}$ & $\begin{array}{c}\text { Minin } \\
\mathrm{g}\end{array}$ & $\begin{array}{c}\text { IC } \\
\text { Techno } \\
\text { logy }\end{array}$ \\
\hline VA/e & 625 & 806 & 3129 & 711 & 525 \\
\hline Salary/e & 464 & 550 & 503 & 637 & 364 \\
\hline Difference & 161 & 256 & 2626 & 74 & 161 \\
\hline
\end{tabular}

The reason for the great difference of Agriculture ought to be caused by the small number of top managers in the Agricultural sector. In contrast, the four other sectors demonstrate very low values of VA/e. The Mining sector for instance proves to have the smallest difference between VA/e and Salary/e, with a value of only 74. This is alarmingly low considering all the other "stakeholders" that are to take part of the value added after salary costs. However, as these companies' value and business operations consist primarily of their employees, this figure could be adequate.

The following statistics summarizes the regression analysis and indicates that there is a medium strong correlation between VA/e and Salary/e on an industry sector basis; on decision scope (Summary Model);
a). Predictors: (Constant), data collection
b). $\mathrm{p}$-value $=0.081$
c). Significant level=95\%
d). Beta Value of 0.23 (Coefficients)
e). Adjusted R, squared $=0.05$

\subsection{Company Size}

In Table 4 below the same descriptions of the statistical data, as in the two previous tables above, can be found regarding company size. The Large companies have the lowest mean values, while the Small companies 
demonstrate the highest mean values and the Medium sized companies in between the other two, both regarding VA/e and SEV/e. The same trends can be found regarding the median values. The Small companies have the largest standard deviation. The other two size segments have both much lower values, especially the larger companies. This difference is also revealed when comparing the largest and smallest values. The reason for this deviation is because the Small companies contain mainly a mix of Agricultural companies and Mining companies. These two sectors are extremes concerning both VA/e and SEV/e, i.e. mining have low VA/e and SEV/e and the Agricultural companies have very high values regarding VA/e as well as SEV/e.

Table 4. Statistical Descriptions by Company size

\begin{tabular}{|c|c|c|c|c|c|c|}
\hline & \multicolumn{2}{|c|}{ Large } & \multicolumn{2}{c|}{ Medium Sized } & \multicolumn{2}{c|}{ Small } \\
\hline & VA/e & SEV/e & VA/e & SEV/e & VA/e & SEV/e \\
\hline Mean & 660 & 1773 & 1406 & 5144 & 2111 & 9208 \\
\hline Median & 609 & 1370 & 753 & 2343 & 880 & 3958 \\
\hline Standard Deviation & 316 & 2179 & 1852 & 6929 & 2375 & 11170 \\
\hline Large & 1427 & 10984 & 7784 & 31536 & 8567 & 60743 \\
\hline Small & 332 & 337 & -449 & 236 & 356 & 433 \\
\hline
\end{tabular}

The same trends as was mentioned above can be found with reference to solely the largest values when comparing VA/e and SEV/e. However, the smallest values of VA/e and SEV/e show a different picture. The values of $\mathrm{VA} / \mathrm{e}$ and SEV/e are relatively correlated regarding large companies. The biggest difference is found within the Medium sized companies, in which the smallest value of VA/e is -449 and 236 for SEV/e.

The following statistics summarizes the regression analysis and indicates that there is even a much significantly stronger correlation between $\mathrm{VA} / \mathrm{e}$ and SEV/e on company size basis, on decision scope (Summary Model);
a). Predictors: (Constant), data collection
b). p-value=1.63E-13
c). Significant level= $95 \%$
d). Beta Value of 0.81 (Coefficients)
e). Adjusted R, squared $=0.65$

\subsection{Company Age}

In Table 5 below the same descriptions of the data, divided by company age can be viewed. The old companies prove to have the lowest mean values, regarding both VA/e and SEV/e. The low values originate from the fact that the majority of these companies mainly consist of Services. The Young companies have the largest mean value for SEV/e at 5 523, though the
Medium aged companies are not far off at 5371. Concerning the mean Value of VA/e, the medium aged companies' holds the largest value. Regarding the Median values the Old companies as before holds the lowest values of VA/e and SEV/e. The Medium aged and Young companies median values, as for the mean values, are very much alike, i.e. 753 and 759 for VA/e and 2202 and 2 170 for SEV/e. This cannot be explained by the composition of companies in these two age segments, instead this similarity could actually be caused by a coincidence. The Medium aged companies consist of all the five sectors while the Young companies consist mainly of Mining.

Interesting to observation is the standard deviation for the Old companies. The standard deviation for VA/e proves to be higher than the SEV/e, something that has not occurred previously in the descriptions. The values for VA/e and SEV/e are also very similar at 1584 and 1560. The standard deviation for the two other age segments are fairly similar, though the Young companies have the largest values of SEV/e and the Medium aged companies have the largest values regarding VA/e. The Old companies have the largest values, both concerning VA/e and SEV/e at 8576 and 60743 respectively, which is interesting considering that these companies had the lowest standard deviation.

Table 5. Statistical Description by, Company Age

\begin{tabular}{|c|c|c|c|c|c|c|}
\hline & \multicolumn{2}{|c|}{ Old } & \multicolumn{2}{c|}{ Medium Aged } & \multicolumn{3}{c|}{ Young } \\
\hline & VA/e & SEV/e & VA/e & SEV/e & VA/e & SEV/e \\
\hline Mean & 1057 & 4887 & 1748 & 5371 & 1231 & 5523 \\
\hline Median & 687 & 1499 & 753 & 2202 & 759 & 2170 \\
\hline Standard Deviation & 1584 & 1560 & 2130 & 6955 & 1479 & 7151 \\
\hline Large & 8567 & 60743 & 8119 & 31536 & 6199 & 29775 \\
\hline Small & 412 & 337 & 332 & 236 & -449 & 433 \\
\hline
\end{tabular}

The following statistics summarizes the regression analysis and indicates the highest significantly stronger correlation between VA/e and SEV/e on company age basis; on decision scope (Summary Model);

a). Predictors: (Constant), data collection

b). $\mathrm{p}$-value $=2.14 \mathrm{E}-30$

c). Significant level= $95 \%$

d). Beta Value of 0.96 (Coefficients)

e). Adjusted R, squared $=0.93$

\subsection{IC Multiplier}

For the purposes of this study the Intellectual Capital Multiplier is calculated by dividing Structural Capital (SC) with Human Capital (HC).To calculate the SC/HC-ratio the researcher examined each company thoroughly in order to come up with an approximation of the IC Multiplier. This approximation is calculated by stating 
that a company's HC-ratio equals its salaries divided by its VA. Since the SC-ratio equals 1-HC this approximation gives the researcher SC, $\mathrm{HC}$ and consequently also the IC Multiplier. Using the approximation in calculating the $\mathrm{HC}$ - and SC-ratios shows that the HC, in average, accounts for 63 percent of the total Intellectual Capital value. This HC-value must be seen as surprisingly high. As implied by the term IC Multiplier the SC-ratio should be at least equal to the HC-ratio. Otherwise erosion rather than a multiplication of the $\mathrm{HC}$ is occurring here.

The argument is with the diverse aspects of the five industries on this study, one might expect the SC/HC-ratio to differ between these industries [18]. As presented in Table 6 below, the difference between the industry sectors also proves to be evident, although the outcome does not completely correlate with the researchers thoughts.

Table 6. Average Proportions by Industry Sector

\begin{tabular}{|c|c|c|c|c|c|}
\hline & $\begin{array}{c}\text { Servi } \\
\text { ces }\end{array}$ & $\begin{array}{c}\text { Manufact } \\
\text { uring }\end{array}$ & $\begin{array}{c}\text { Agric } \\
\text { ulture }\end{array}$ & $\begin{array}{c}\text { Minin } \\
\text { g }\end{array}$ & $\begin{array}{c}\text { IC } \\
\text { Technolo } \\
\text { gy }\end{array}$ \\
\hline $\begin{array}{c}\text { Structural } \\
\text { Capital }\end{array}$ & 0,31 & 0,63 & 0,30 & 0,20 & 0,32 \\
\hline Human Capital & 0,69 & 0,37 & 0,70 & 0,80 & 0,68 \\
\hline IC Multiplier & 0,54 & 6,05 & 0,63 & 0,16 & 0,53 \\
\hline
\end{tabular}

The mining sector, with focus on man-hours, does in fact show the highest HC-ratio, with HC about four times as large as SC ratio. What this implies is that most of company value lies with employees. When the employees go home at night, so does most of the company value. The process of transforming HC into SC is therefore of utter importance for these companies. An average IC Multiplier value of 0,16 further strengthens the previous assertion, as there in this sector lays a major erosion in the value created by the HC. A larger amount of SC would probably also stabilize these companies' stocks, thus halting the volatility that historically has characterized the Mining stocks. Agricultural sector, with the second highest HCratio, does also correspond with the researcher's expectations. With focus on research and development, a lot of value obviously lies in the tacit knowledge of the employees. But with an average IC Multiplier of below 1, this tacit knowledge is still not employed to its full potential.

The following statistics summarizes the regression analysis and indicates that there is significantly strong correlation between VA/e and IC Multiplier on industry sector basis; on decision scope (Summary Model);

a). Predictors: (Constant), data collection

b). $\mathrm{p}$-value=3.09E-73

c). Significant level $=95 \%$

d). Beta Value of 0.92 (Coefficients)

e). Adjusted R, squared $=0.84$

When dividing the companies by size, presented in Table 7 below, the average SC and the average HC are quite similar for all three segments. They do also, logically, resemble the ratios for all companies, with HC about twice the size of SC. However, more interesting is the difference in IC Multiplier, although the most probable explanation for this change in value is the low amount of employees in the Manufacturing sector portion of the small companies.

The following statistics summarizes the regression analysis and indicates that there is significantly strong correlation between VA/e and IC Multiplier on company size basis; on decision scope (Summary Model);

a). Predictors: (Constant), data collection

b). p-value=2.27E-23

c). Significant level= 95\%

d). Beta Value of 0.89 (Coefficients)

e). Adjusted R, squared $=0.80$

Table 7. Average Proportions by Company size

\begin{tabular}{|c|c|c|c|}
\hline & Large & Medium sized & Small \\
\hline Structural Capital & 0,35 & 0,39 & 0,39 \\
\hline Human Capital & 0,67 & 0,63 & 0,63 \\
\hline IC Multiplier & 0,65 & 1,87 & 3,11 \\
\hline
\end{tabular}

Considering the companies divided by age, in Table 8 below, the results are rather similar to those in the table above. All three segments show HC and SC ratios in the vicinity of the ones for all companies, although there is a difference between the Young and Medium aged companies. Notable is also that all three segments have IC Multipliers above 1.

The following statistics summarizes the regression analysis and indicates that there is significantly strong correlation between VA/e and IC Multiplier on company age basis; on decision scope (Summary Model);
a). Predictors: (Constant), data collection
b). p-value $=5.32 \mathrm{E}-39$
c). Significant level=95\%
d). Beta Value of 0.98 (Coefficients)
e). Adjusted R, squared $=0.97$

Table 8. Average Proportions by Company Age

\begin{tabular}{|c|c|c|c|}
\hline & Old & Medium aged & Young \\
\hline Structural Capital & 0,40 & 0,43 & 0,32 \\
\hline Human Capital & 0,62 & 0,59 & 0,70 \\
\hline IC Multiplier & 1,34 & 2,81 & 1,26 \\
\hline
\end{tabular}

\section{Conclusion and Recommendations}

The purpose of this study has been to examine whether there is a correlation between the intellectual capital and the market value of selected listed companies on the Zimbabwe Stock Exchange and further examine IC Multiplier as a possible indicator for leveraging Intellectual Capital. The researcher considers this purpose to be fulfilled since propositions defined for the purposes of this study have been statistically tested.

Proposition 1: There is a significant relationship between companies' value added per employee and their share price value per employee when comparing all the selected companies.

The first proposition proves that there, in general, is a correlation between companies' value added and their stock exchange value. The correlation is also significantly strong. What this strong correlation further implies is that most company's perceived value, in today's knowledge economy, is related to the company's intellectual capital.

Proposition 2: There is a significant relationship between companies' value added per employee and their share price value per employee when comparing companies by industry sector.

The second hypothesis proves that there is a medium strong correlation when comparing companies by industry 
sector mainly because of the variations in companies value added per employee and their share price per employee, industry sector by industry sector. The sectors also differ from each other because the focus is on manhours. In other words the value added can therefore be traced almost solely to the employees.

Proposition 3: There is a significant relationship between companies' value added per employee and their share price value per employee when comparing companies divided by company size.

Testing the third proposition, this study proves that there in fact is a significant relationship between the intellectual capital and the market value when dividing the companies into size segments. The findings, however, also prove that there is no identifiable size pattern, i.e. the correlation is not as strong within the larger companies, compared to the correlation of the medium or small companies.

Proposition 4: There is a significant relationship between companies' value added per employee and their share price value per employee when comparing companies divided by company age.

The study further proves, regarding the fourth proposition, that there also is a clear relationship between the intellectual capital and the market value of the companies, when they are divided into segments according to age. What is most interesting about these results is that there in fact is a relationship which proves that the older a company gets, the clearer the correlation becomes between companies' intellectual capital and their market value, i.e. the sought pattern becomes more legible over time. The researcher believes that this observed fact originates from that the investors/financial markets knowledge of the companies' intellectual capital increases over time.

Proposition 5: There is a significant relationship between companies' IC Multiplier and their value added per employee.

The fifth proposition has been proven to be correct in this study, i.e. there is, according to the approximations made, a correlation between the IC Multiplier and the intellectual capital. The findings further show strong correlations, especially concerning companies divided by size and age. However, the results also prove that most companies do not have enough structural capital to support the individuals, i.e. the human capital. The conclusion can therefore be drawn that Zimbabwean companies in general cannot exploit the value of its employees' brains to their full potential. In fact the low amount of structural capital that exists within companies constrains the employees, i.e. the employees' knowledge is being hollowed out. The study also indicates that there seem to be a relationship between the IC Multiplier and market value. The reason for this is that the IC Multiplier affects the intellectual capital, which in turn affects the market value. The leverage effect regarding these both relationships means that a small improvement of the $\mathrm{SC} / \mathrm{HC}$-ratio dramatically can affect the market value.

\section{References}

[1] Johnson, M, "Intellectual Capital`s Leverage on Market Value”, Book House.

[2] Lev, B 2000, "Knowledge and shareholder value", http://www.stern.nyu.edu/ blev/knowledge\&shareholdervalue.doc, download May 15 2002, 2002.

[3] Gu, F, and Lev, B, "Intangible Assets-Measurement, drivers, usefulness”, http://www.stern.nyu.edu/ blev/intangible-assets.doc, download April 10 2002, 2001.

[4] Edvinsson, L, and Malone, M. S, "Intellectual Capital: realizing your company's true value by finding its hidden brainpower", Harper Business, 1997.

[5] Pulic, A, "VAIC-An Accounting Tool for IC Management", http://www.measuring-ip.at/Papers/ham99txt.htm, download April $15^{\text {th }} 2002,2000$.

[6] Rylander, A, Jackobsen, K., and Roos, G, "Towards improved information disclosure on intellectual capital", International Journal of Technology Management, Volume 20(5/6/7/8), 715741, 2000.

[7] Bontis, N, "There`s a price on your head: managing intellectual capital strategically”, Business Quarterly, Summer, 40-47, 1996.

[8] Bontis, N, "Intellectual capital: an exploratory study that develops measures and models” Management Decision, Volume 36(2), 6376, 1998.

[9] Bontis, N, "Managing Organizational Knowledge by Diagnosing Intellectual Capital: Framing and advancing the state of the field", International Journal of Technology Management, Volume 18(5/6/7/8), 433-462, 1999.

[10] Collis, D.J, and Montgomery, C.A, "Competing on resources: strategy in the 1990s”, Harvard Business Review, 118-128, 1995.

[11] Guthrie, J, "The management, measurement and the reporting of intellectual capital, Journal of Intellectual Capital, Volume 2(1), 27-41, 2001.

[12] Edvinsson, L, "Developing IC at Skandia”, Long Range Planning, Volume 30(3), 320-321-366-373. 1997.

[13] Dzinkowski, R, “The measurement and management of intellectual capital: an introduction”, Management Accounting: Magazine for Chartered Management Accountants, Volume 78(2), 32-36, 2000.

[14] Pike, S, Rylander, A., and Roos, G, "Intellectual capital management disclosure”, In Choo, C.W., and Bontis, N (Ed), The Strategic Management of Intellectual Capital and Organizational Knowledge: A Selection of Readings, Oxford University Press, New York, NY, 2001.

[15] Sveiby, K, "The new organizational wealth: managing \& measuring knowledge-based assets”, Berrett-Koehler, 1997.

[16] Sveiby, K., Arbetsgruppen, K, "Den osynliga balansräkningen", Affärsvärlden förlag AB, www.intellectualcapital.org 2000, Curry, A., and Cavendish, S (editors), download April $14^{\text {th }} 2002$ http://www.intellectualcapital.org/evolution/index.html, 1990.

[17] Barney, J.B, "Firm resources and sustained competitive advantage”, Journal of Management, Volume 17, 99-120, 1991.

[18] Edvinsson, L, "Corporate Longitude: navigating the knowledge economy”, Book house, 2002. 